\title{
PELATIHAN CARA TEKNIK PENGUTIPAN DAN CARA MENGHINDARI TINDAKAN PLAGIAT BAGI PARA GURU SMK MUHAMMADIYAH 3 PEKANBARU
}

\author{
Januar Al Amien*, Sunanto, Desti Mualfah, Baidarus, Evans Fuad, \\ Febby Apri Wenando, Soni \\ Prodi Teknik Informatika, Fakultas Ilmu Komputer \\ Universitas Muhammadiyah Riau \\ email: januaralamien@umri.ac.id
}

\begin{abstract}
Nowadays there are many cases of plagiarism that are becoming our concern. Therefore, the writings on plagiarism are one of the things that is important to be understood by the world of education, to avoid plagiarism. Respect, acknowledge and give credit for the work of others is a necessity in producing writing. We all know that science is developed based on pre-existing science. So that there is no need to hesitate for anyone among Educators when composing scientific papers / written works, mentioning the reference sources. This must be understood as intellectual honesty that will not reduce the weight of our writing. Mention honestly, the source of reference that we use, or quote, so that it will be seen clearly, which parts of our work are ideas or taken from dictionaries, encyclopedias, articles, reports, books, magazines, internet, and others.
\end{abstract}

Keywords: plagiarism, Citiation, Devotion.

\section{Abstrak}

Saat ini mulai muncul beberapa kasus plagiarisme yang menjadi perhatian kita, Oleh karena itu tulisan mengenai plagiarisme menjadi salah satu hal yang penting dipahami oleh dunia pendidikan, untuk menghindarkan diri dari praktik-praktik plagiat. Menghormati, mengakui dan memberikan penghargaan atas karya orang lain menjadi satu keharusan dalam memproduksi karya tulis. Kita ketahui bersama bahwa ilmu pengetahuan dikembangkan berdasarkan pada ilmu pengetahuan yang sudah ada sebelumnya. Sehingga tidak perlu raguragu bagi siapapun kalangan Pendidik ketika menyusun karya ilmiah/karya tulis, menyebutkan sumber rujukan. Hal ini harus dipahami sebagai kejujuran intelektual yang tidak akan menurunkan bobot karya tulis kita. Sebutkanlah dengan jujur, sumber rujukan yang kita gunakan, atau melakukan kutipan, sehingga akan terlihat jelas, bagian mana dari karya kita yang merupakan ide atau diambil dari kamus, ensiklopedi, artikel, laporan, buku, majalah,internet, dan lain sebagainya.

Kata kunci: Plagiat, Kutipan, Pengabdian.

\section{PENDAHULUAN}

Seiring berkembangnya ilmu pengetahuan dan teknologi, maka kita pun dituntut untuk selalu mengembangkan dan mempublikasikan hasil dari perkembangan ilmu pengetahuan dan teknologi tersebut. Salah satu bentuk pengembangan tersebut ialah dengan cara membuat karya tulis ilmiah, buku since, dan lain sebagainya. Dalam pembuatan karya ilmiah maupun buku-buku since tentu tidak akan lepas dari yang namanya sumber rujukan. Sumber rujukan dalam hal ini adalah teori-teori dari berbagai sumber baik diambil dari kamus, 
ensiklopedi, artikel, laporan, buku, majalah, internet, agar terhindar perbuatan plagiat

Kutipan adalah gagasan, ide, pendapat yang diambil dari berbagai sumber. Proses pengambilan gagasan itu disebut mengutip. Gagasan itu bisa diambil dari kamus, ensiklopedi, artikel, laporan, buku, majalah, internet, dan lain sebagainya. Mengutip bukanlah sesuatu hal yang bisa seenaknya saja kita buat, namun ada beberapa aturan mengutip yang perlu kita ketahui. Aturan-aturan mengutip ini sangat penting untuk diketahui agar dalam pembuatan karya tulis, catatan kaki dan daftar pustaka tidak terjadi kesalahan yang berakibat fatal bagi kebenaran penguatan argumen dalam karya tulis kita.

Sungguh ironis jika sampai saat ini masih banyak tidak mengetuhui yang terkadang masih salah dalam melakukan kutipan bahkan tindakan disengaja. Sehingga Beberapa tindakan plagiat terjadi di sekitar kita. Tentu saja hal ini cukup menjadi perhatian kita semua, sehingga menjadi sangat penting bagi kita untuk mengantisipasi tindakan ini. Tindakan plagiat akan mencoreng dan memburamkan dunia pendidikan kita dan tidak berlebihan jika plagiarisme dikatakan sebagai kejahatan intelektual.

\section{METODE PENELITIAN}

Kepedulian Lembaga Perguruan Tinggi kepada guru-guru dalam rangka meningkatkan kualitas pendidikan adalah tinggi, ini merupakan Tri Dharma Perguruan Tinggi. Untuk merealisasikan program tersebut diperlukan suatu rencana.

Program pengabdian pada masyarakat yang dilaksanakan dalam kegiatan ini adalah Pelatihan Cara Teknik Pengutipan Dan Cara Menghindari Tindakan Plagiat Bagi
Para Guru SMK Muhammadiyah 3 Pekanbaru.

.Materi pelatihan ini menitikberatkan pada pembuatan karya Ilmiah, sehingga diharapkan guru-guru tersebut dapat menghasilkan karya Ilmiah dalam di bidangnya masingmasing. Pelaksanaan kegiatan ini didukung oleh para Dosen Teknik Informatika di Fakultas Ilmu Komputer, Kegiatan ini dilaksanakan di SMK Muhammadiyah 3 Pekanbaru pada Hari Kamis Tanggal 12 Bulan Oktober 2018. Peserta yang terlibat sebanyak 34 orang yang merupakan majelis guru dilingkungan SMK Muhammadiyah 3 Pekanbaru Meliputi beberapa tahapan kegiatan di lihat dari tabel berikut :

Tabel 1. Tahapan Kegiatan

\begin{tabular}{|c|c|c|}
\hline 1 & Persiapan & 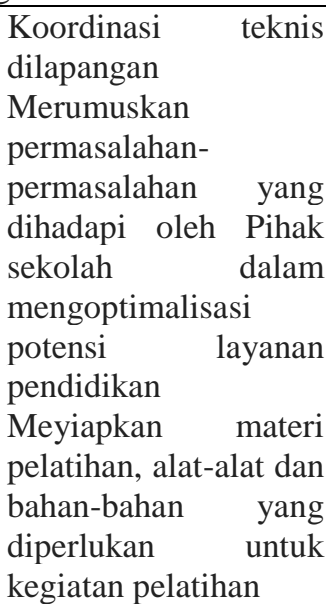 \\
\hline 2 & Pelaksanaan & $\begin{array}{l}\text { Penyampaian Materi } \\
\text { cara penggutipan yang } \\
\text { benar dan } \\
\text { menghindari Plagiat } \\
\text { Mengenalkan aplikasi } \\
\text { Plagirisme dan } \\
\text { pelatihan bagaiamana } \\
\text { penggunaan Aplikasi } \\
\text { tersebut }\end{array}$ \\
\hline 3 & Evaluasi & $\begin{array}{lr}\text { Evaluasi } & \text { hasil kerja } \\
\text { untuk } & \text { mengetahui } \\
\text { kendala } & \text { selama } \\
\text { pelatihan } & \end{array}$ \\
\hline
\end{tabular}

\section{HASIL DAN PEMBAHASAN}

Dalam Pengabdian di SMK Muhammadiyah 3 Pekanbaru yang sudah di laksanakan menitik beratkan 
kepada tulisan ilmiah, baik berupa artikel, karya ilmiah. Adapun kegiatan ini memberikan materi seputar Pengutipan dan Plagiat yang mana nantinya akan berlanjut dengan penggunaan aplikasi Pengecekan aplikasi Plagirisme diantara kegiatan tersebut.

1. Penyampaian Materi Kepada guruguru terkait tentang teknik pengutip, Pengutipan Langsung, Kutipan tidak Langsung dan Kutipan yang telah di kutip beserta contoh

2. Pengenalan Materi tentang pengatuhan agar terhindar dari Plagiat Beserta Software yang lazim di pakai secara online seperti website https://www.grammarly.com/ dan https://www.quetext.com/

3. Dan mendemontrasikan software tersebut agar mengetahui sampai berapa persentasi karya akan dibuat

Kegiatan pengabdian yang dilaksanakan pada guru-guru SMK Muhammadiyah 3 Pekanbaru telah berlangsung dengan baik. Hal ini terlihat dari sambutan positif dan antusiasme dari bapak/ibu guru serta mengikuti Pelatihan dengan baik. Kepala sekolah dan guru-guru menyambut antusias terkait pelaksanaan kegiatan ini dan berharap pelaksanaan kegiatan dapat dilakukan secara kontinu untuk membantu meningkatkan kualitas guruguru.

\section{SIMPULAN}

Ada pun kegiatan pengabdian masyarakat yang telah dilakukan di SMK Muhammadiyah 3 Pekanbaru hasil yang dicapai adalah :

a. Menambah pengetahuan tentang materi Pengutipan dan terhindarnya tindakan Plagiat/Plagirisme

b. Mengaplikasikan cara/teknik pengutipan untuk sebuah karya ilmiyah c. Dapat mengimplemntasikan cara software pengecekan karya ilmiah dengan software plagirsme

Untuk beberapa saran dalam kegiatan Pengabdian masyarakat ini adalah :

a. Untuk kedepannya para guru-guru dapat mengembangkan karya ilmiahnya dengan metode pengutipan yang sudah diberi materi.

b. Agar berhati-hati dalam pengutipan supaya terhindar dalam tindakan kegiatan plagiat dan mengecek software yang sudah di implementasikan ketika kegiatan berlangsung.

\section{UCAPAN TERIMAKASIH}

1. Lembaga Penelitian dan Pengabdian Masyarakat (LPPM) Universitas Muhammadiyah Riau (UMRI) yang telah memberikan dukungan berupa biaya dan motivasi.

2. Kepala Sekolah SMK Muhammadiyah 3 pekanbaru yang telah memfasilitasi kegiatan ini

3. Seluruh Peserta kegiatan yang merupakan para majelis guru dilingkungan SMK Muhammadiyah 3 pekanbaru yang begitu antusias dalam mengikuti kegiatan ini.

\section{DAFTAR PUSTAKA}

[1] Avoiding Plagiarism. http://writing.mit.edu/wcc/avoiding plagiarism

[2] Claubaugh, G.K. \& Rozycki, E.G. (2001). The Plagiarism Book: A Student's Manual.

[3] Peraturan Menteri Pendidikan Nasional Nomor 17 Tahun 2010 tentang Pencegahan dan Penanggulangan Plagiat di Perguruan Tinggi

[4] Reitz, Joan M. Online Dictionaryfor Library and Information Science. Dalam http://www.abcclio.com/ODLIS/odlis_p.aspx 
[5] Soelistyo, H. (2011). Plagiarisme: Pelanggaran Hak Cipta dan Etika. Yogyakarta: Penerbit Kanisius.

[6] Supriyadi, D. (2013). Integritas Akademik. Dalam http://mmr.ugm.ac.id/index.php/aka demik/integritas-akademik

[7] Undang-Undang No. 19 Tahun 2002 tentang Hak Cipta

[8] Zulkarnaen. (2012). Menghindari Perangkap Plagiarisme dalam Menghasilkan Karya Tulis Ilmiah. Makalah. Disampaikan pada Pelatihan Penulisan Artikel Ilmiah, Lembaga Penelitian, Universitas Jambi, 16 Januari 2012. 